\title{
A concise total synthesis of the lichen macrolide (+)-Aspicilin
}

\author{
Christophe Dubost, István E. Markó* and Thomas Ryckmans** \\ *Université catholique de Louvain, Département de chimie, 1 place Louis Pasteur, \\ B-1348, Louvain La Neuve, Belgium. \\ Marko@chim.ucl.ac.be \\ ** Pfizer Global Research and Development, Sandwich, Kent CT13 9NJ, England.
}

\section{NMR spectras}

Part 2 


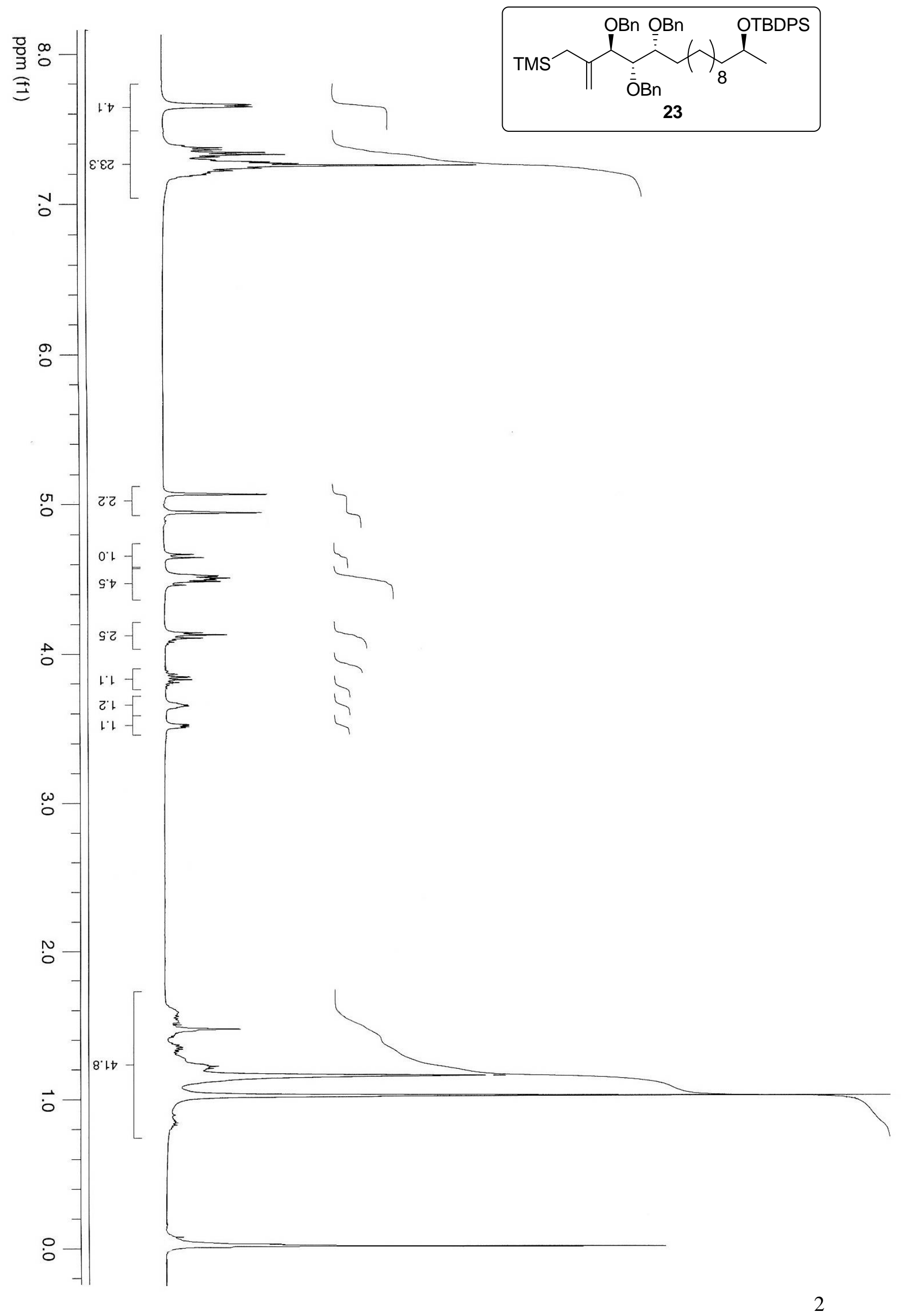




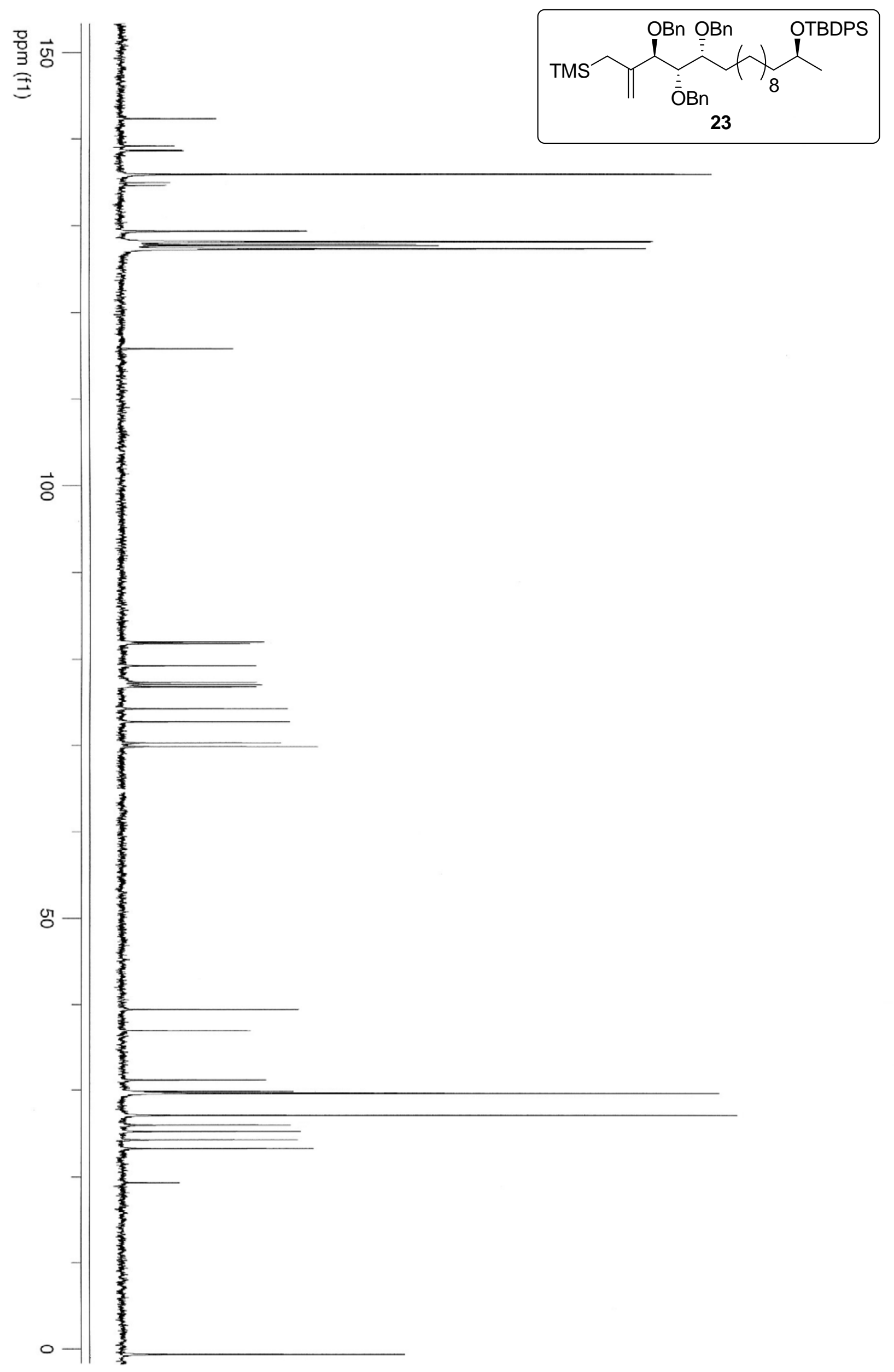

3 


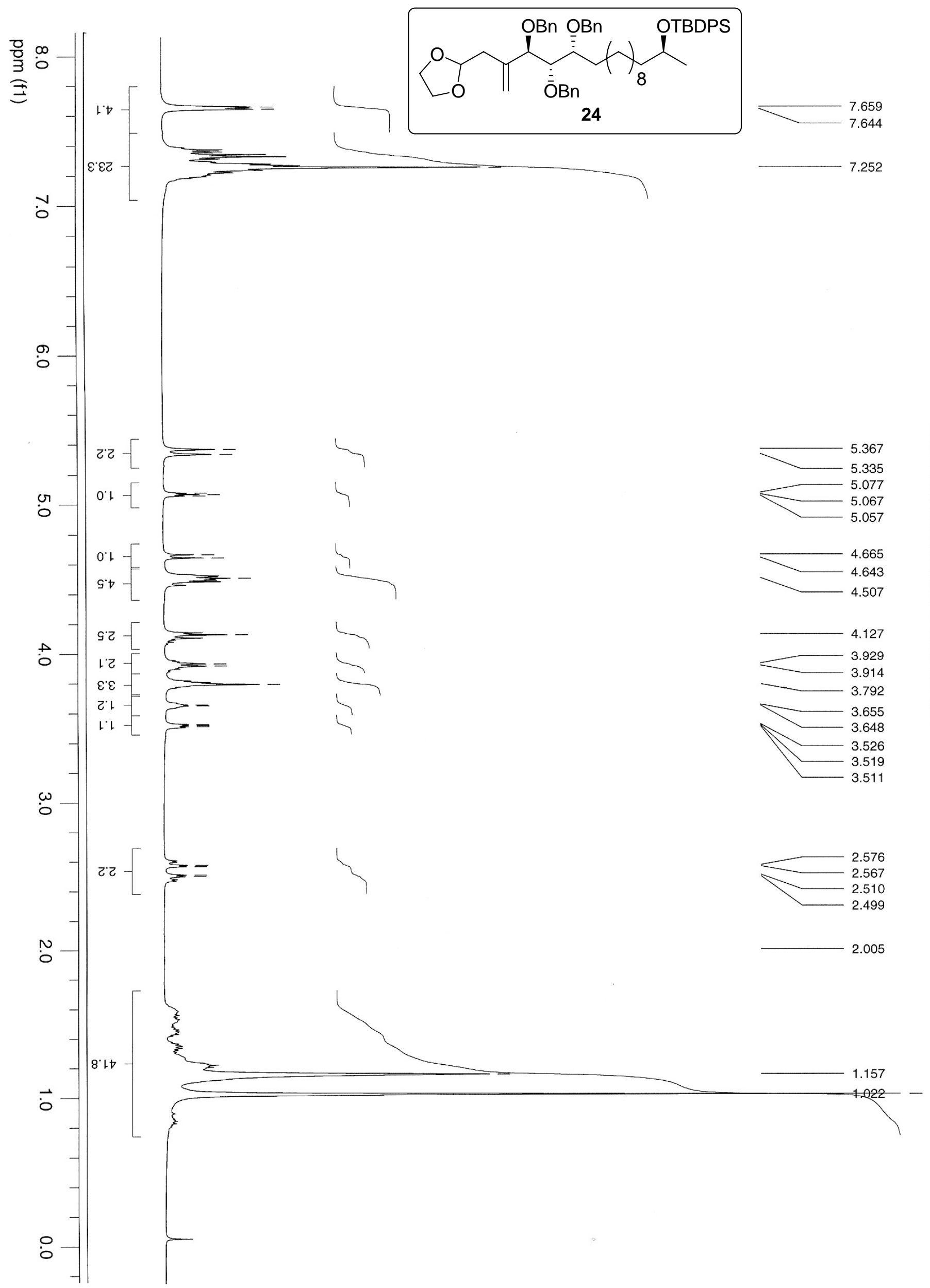



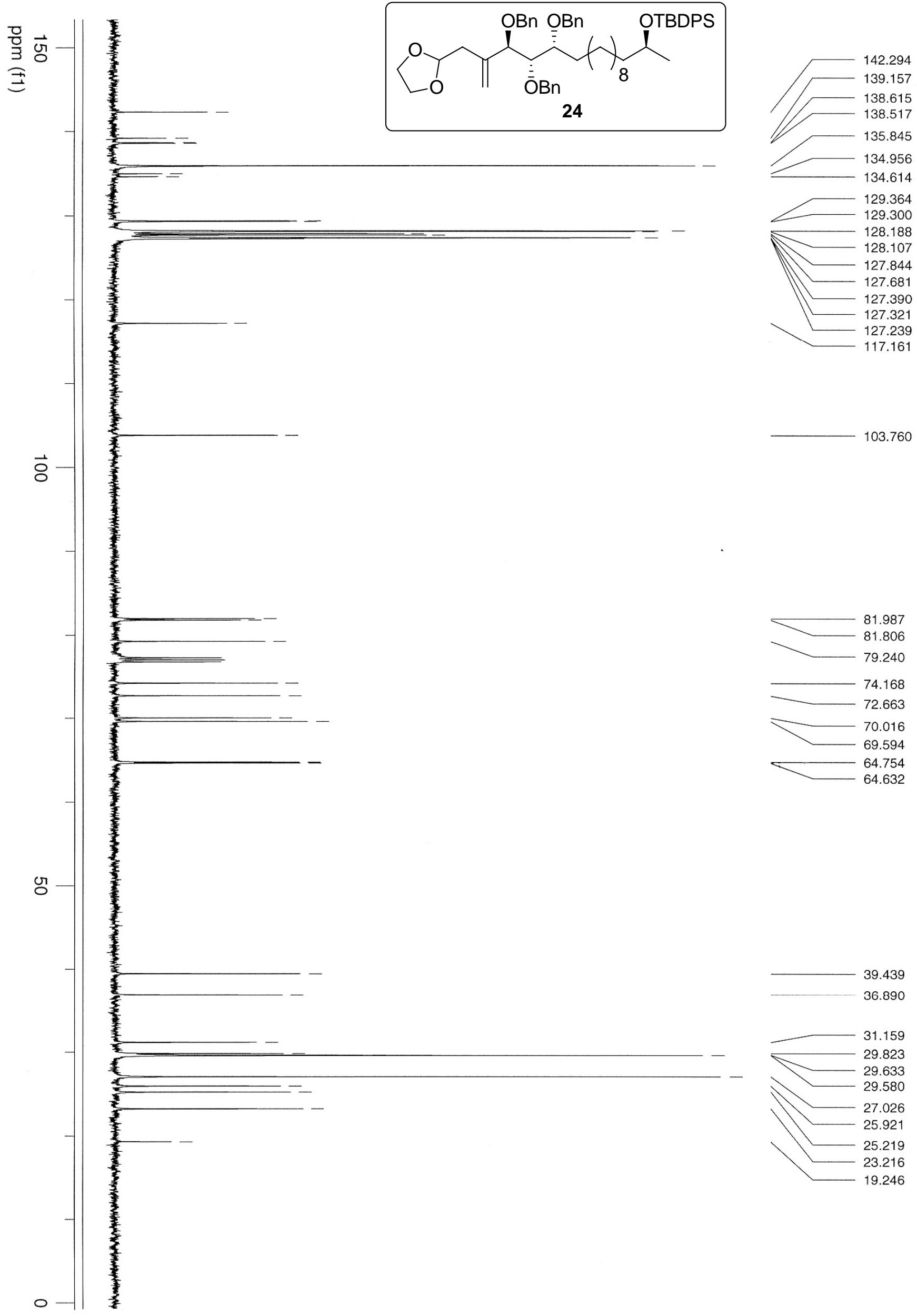

103.760

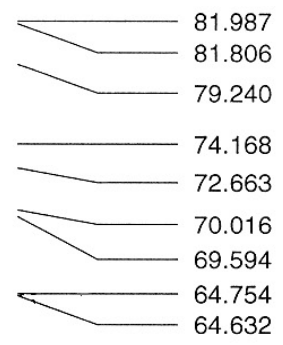

39.439

36.890

31.159

29.823

29.633

29.580

27.026

25.921

25.219

23.216

19.246 


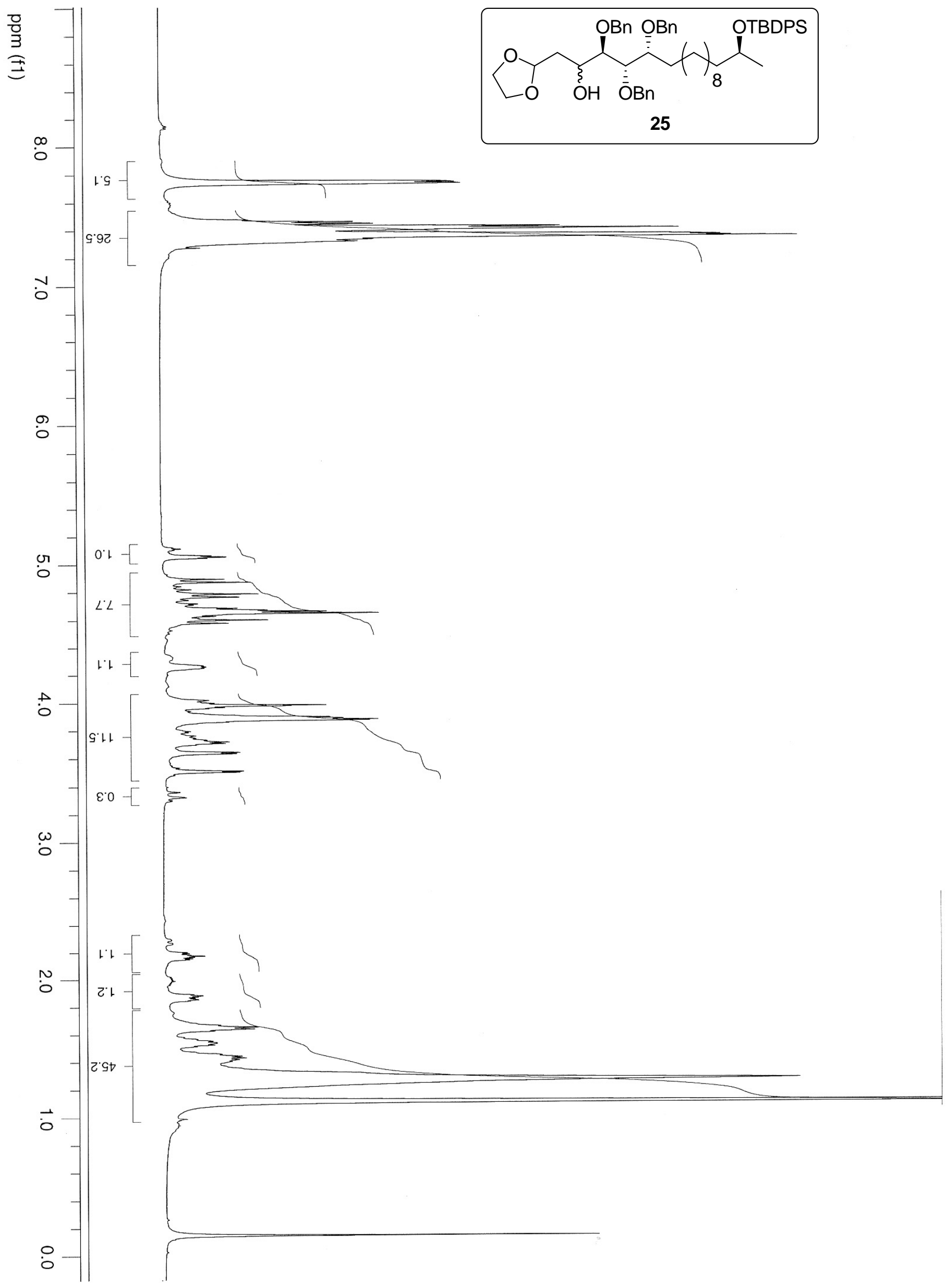




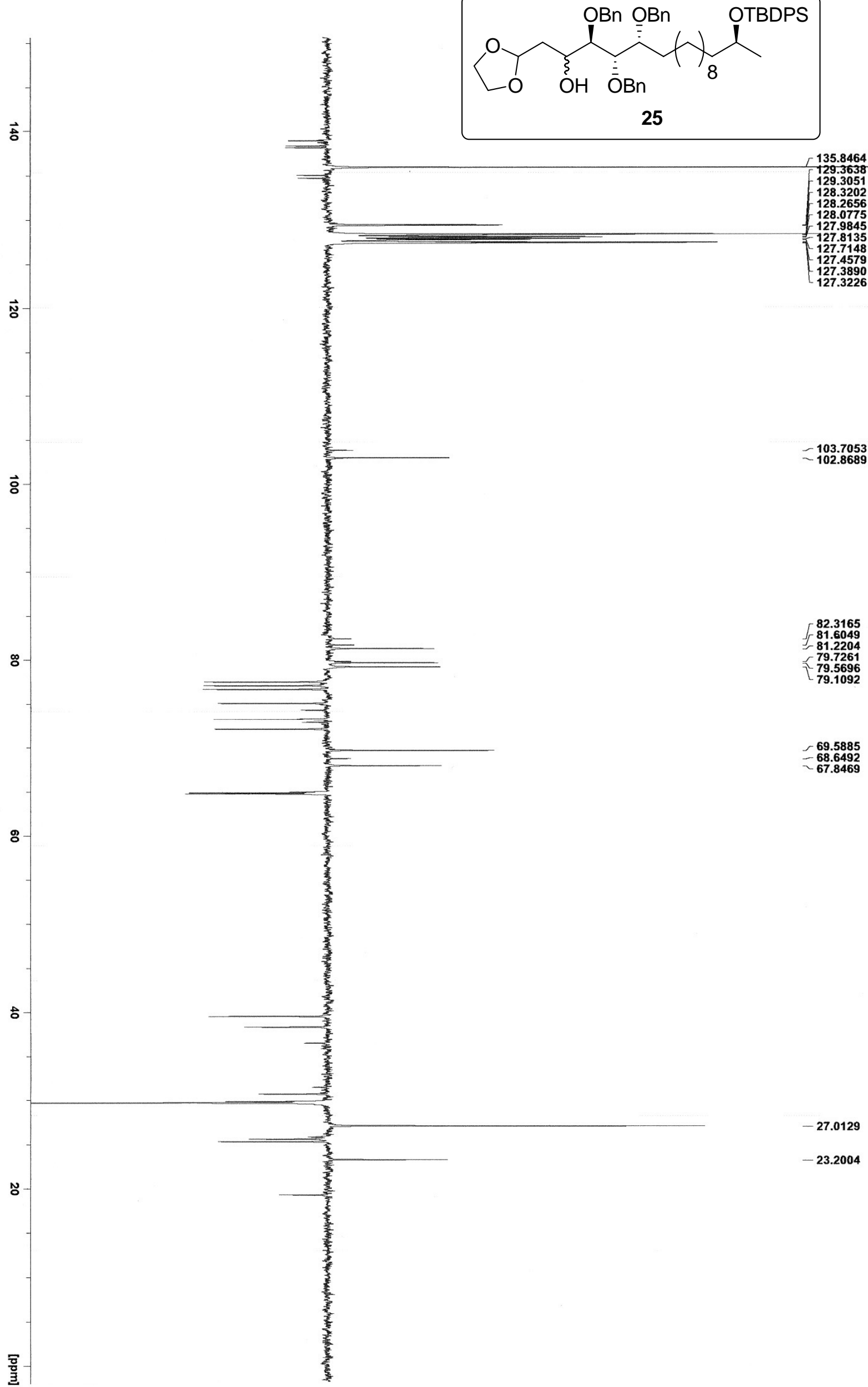




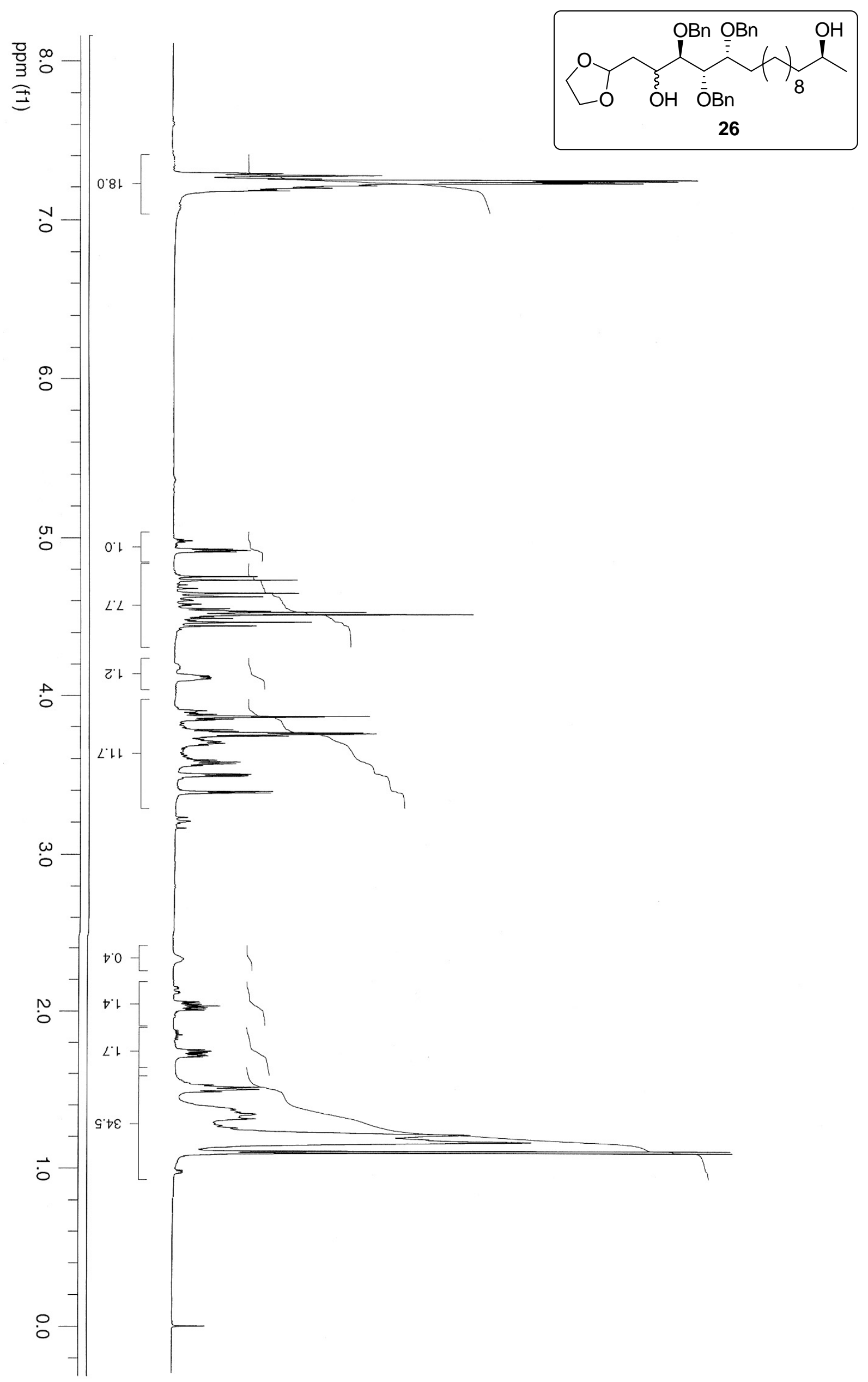




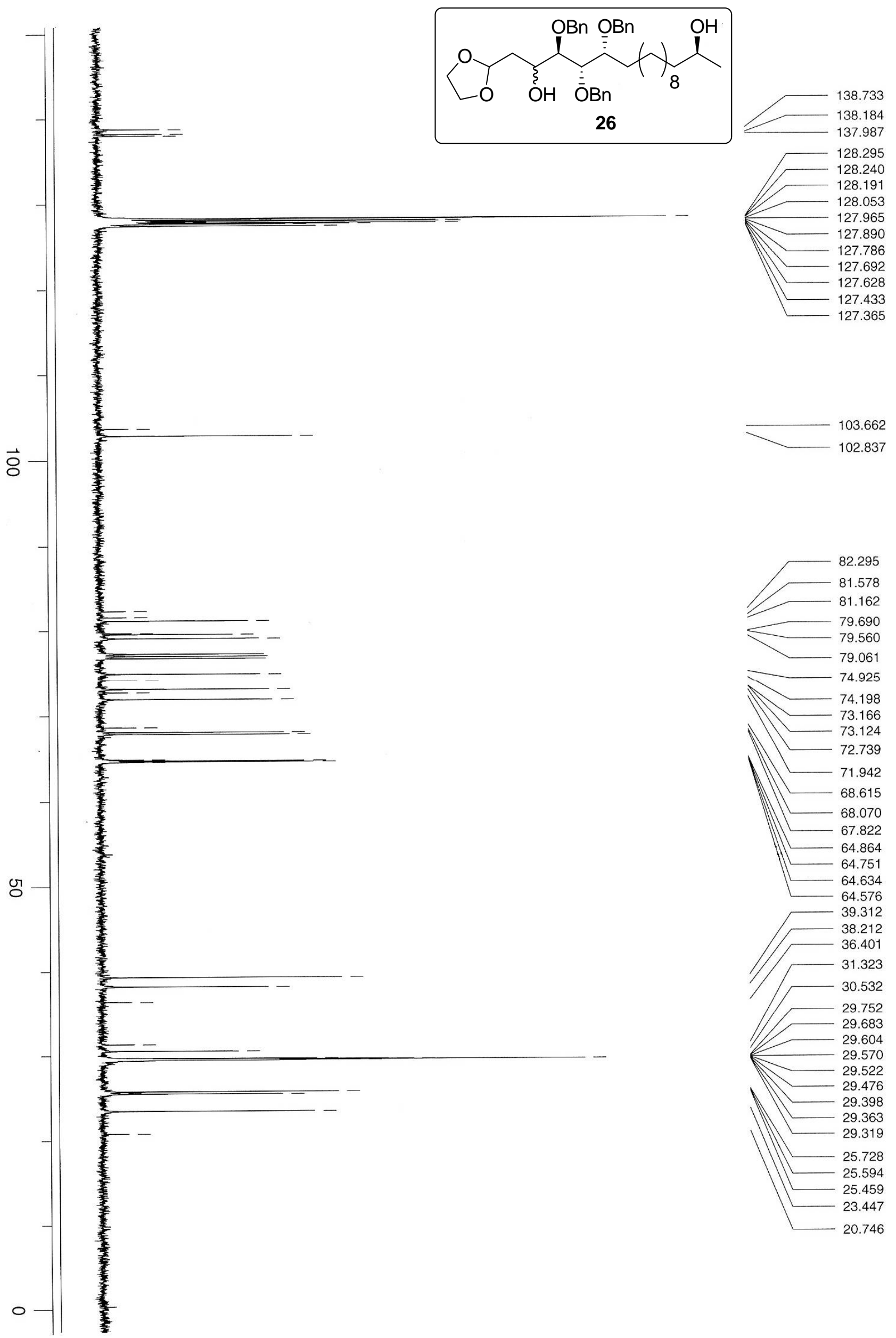

9 
$\frac{7}{0}$
3
을

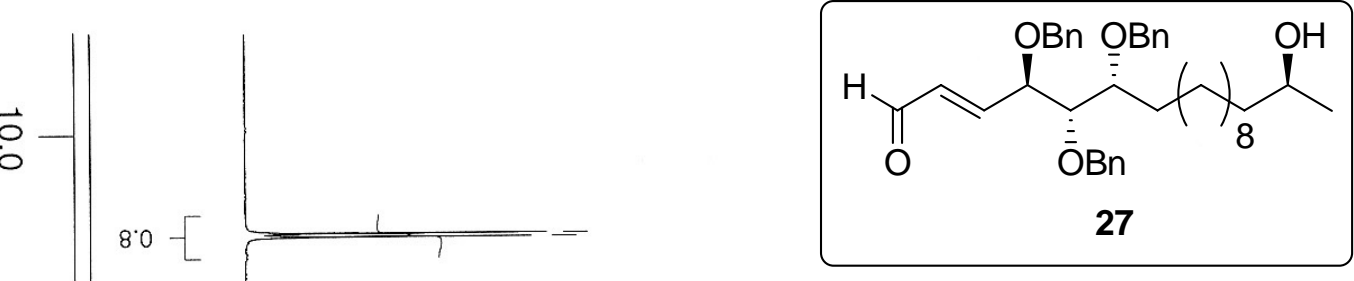

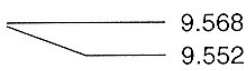

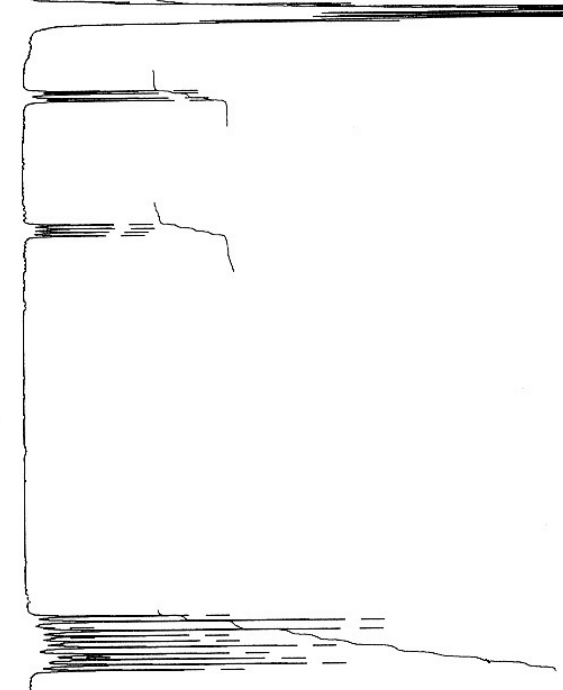

$0 \cdot 2-[$

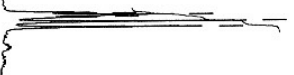

$0.1=-5$
0.5

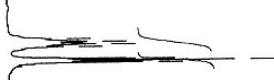

t. - -

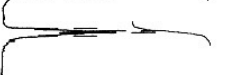

$-\left.\right|_{1 \cdot 0 \varepsilon-[}$

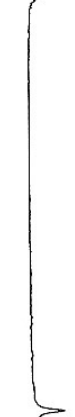
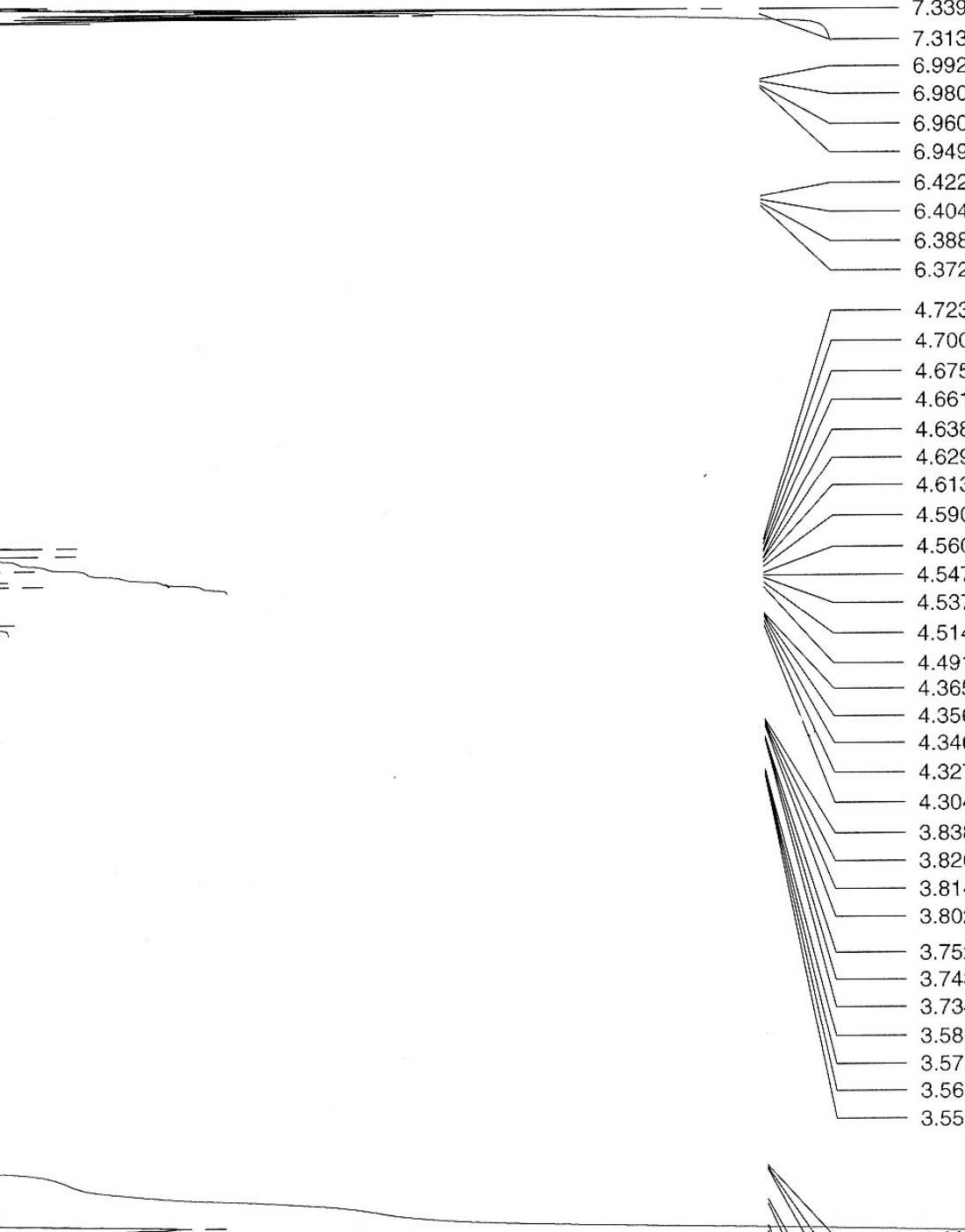

$-6.372$

4.723

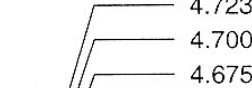

4.675

4.661
4.638

4.613

4.590

4.560

4.547

4.537

$\mathbb{M} 4.514$

4.491

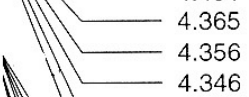

$\mathbb{1} \begin{array}{r}\square .346 \\ -4.327\end{array}$

4.304

3.838

3.826

3.814

3.802

3.752

3.743

3.734

3.586

3.573

3.565

3.552

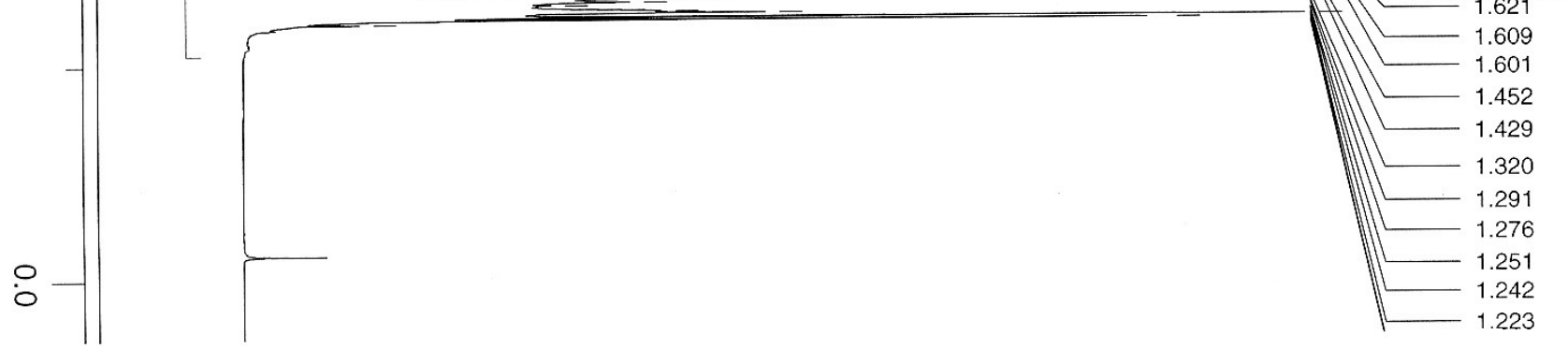




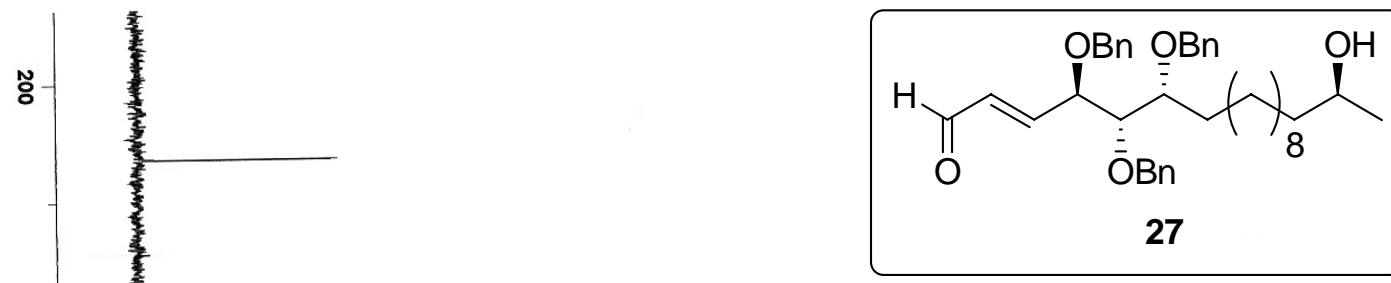

$-193.4309$

$-155.0469$

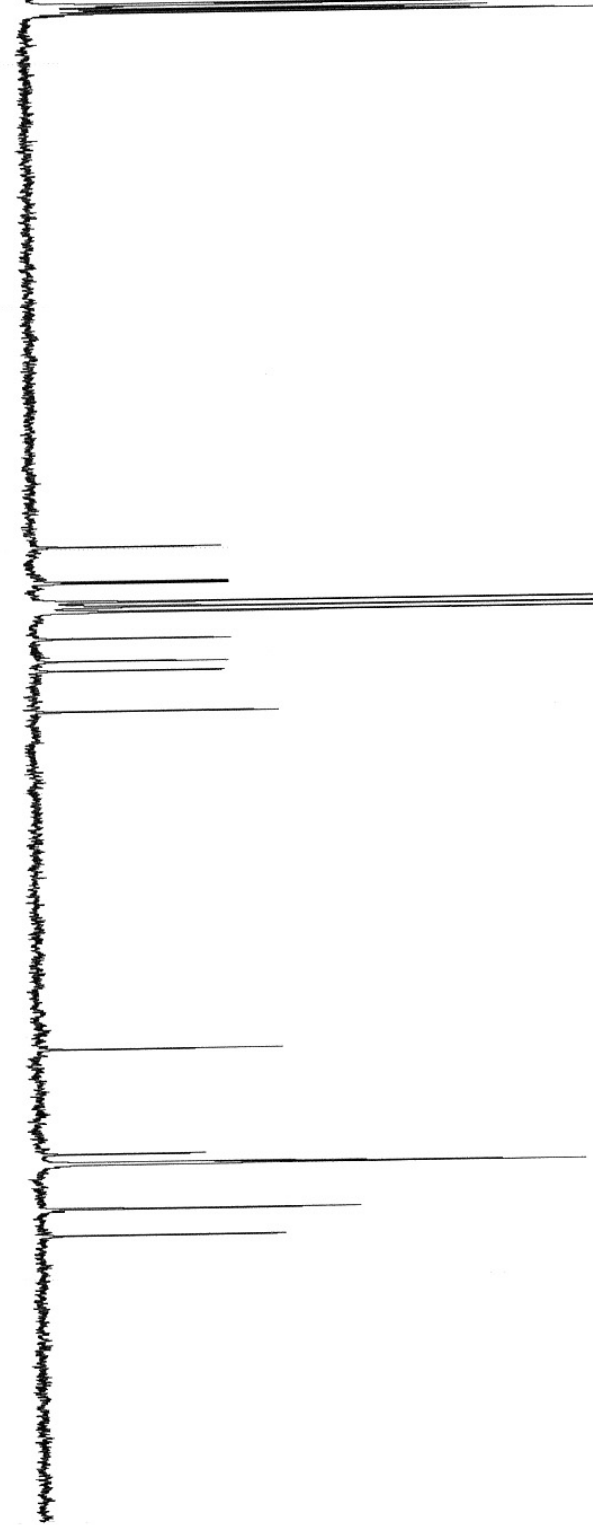

82.1024

79.1498
$\mathbf{7 9 . 0 2 0 4}$

74.2880

72.3621

$-68.0908$ 


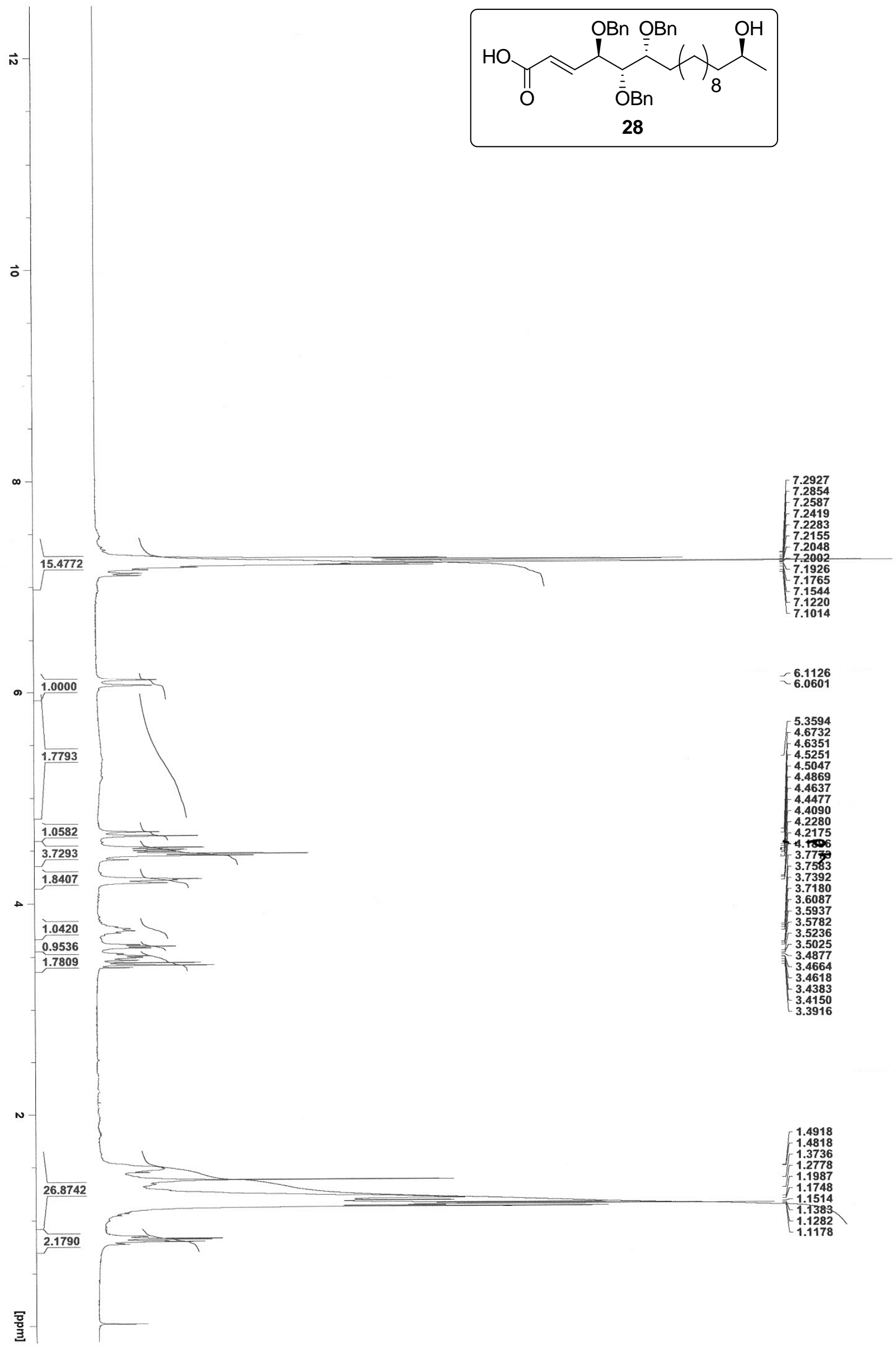




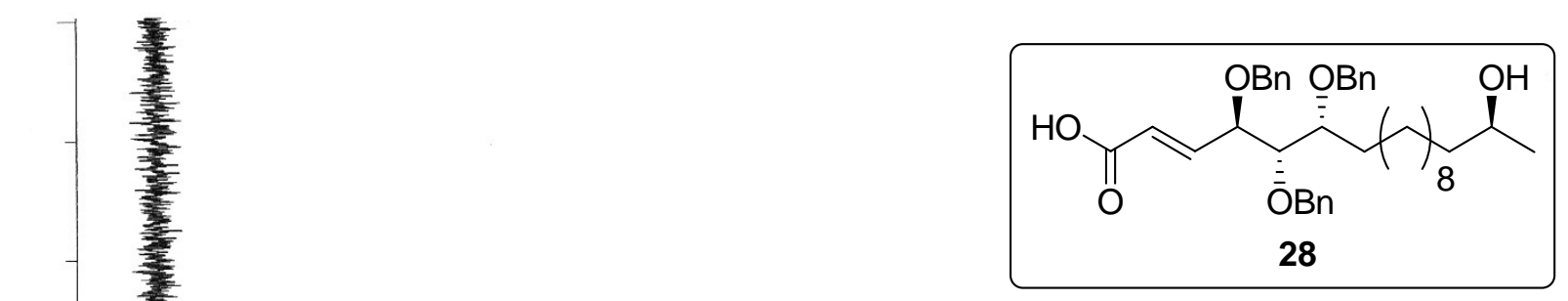

$-148.4639$

138.6077

$+138.0547$

137.7597

$-122.6445$

$\overrightarrow{8}$

당

82.3921

78.9304

74.3967

72.4948

71.3368

$-68.3020$

$-39.2062$

30.5138

30.2964

29.5519

29.4944

29.4301

25.6688

23.4065

$\frac{7}{0}$ 


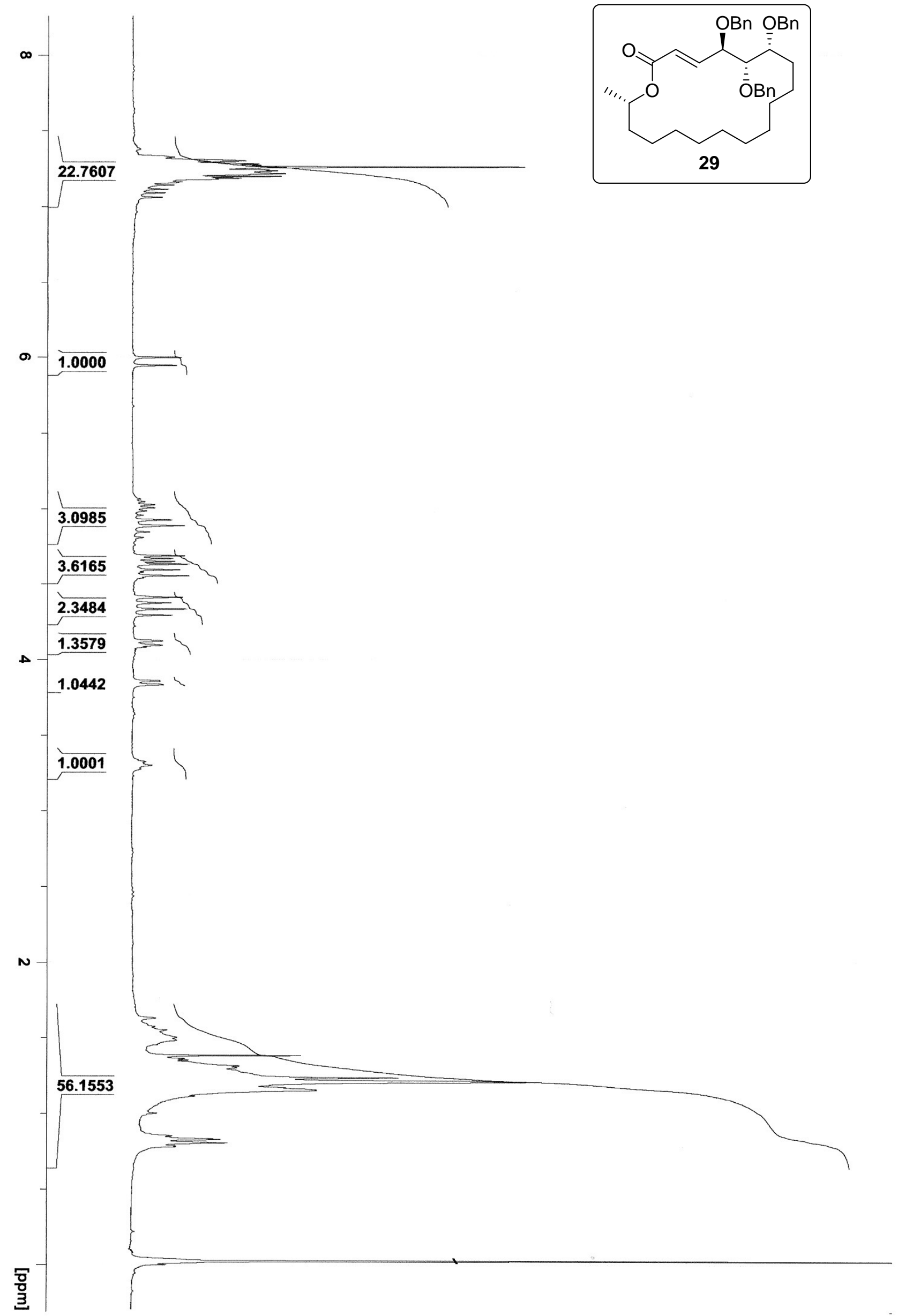




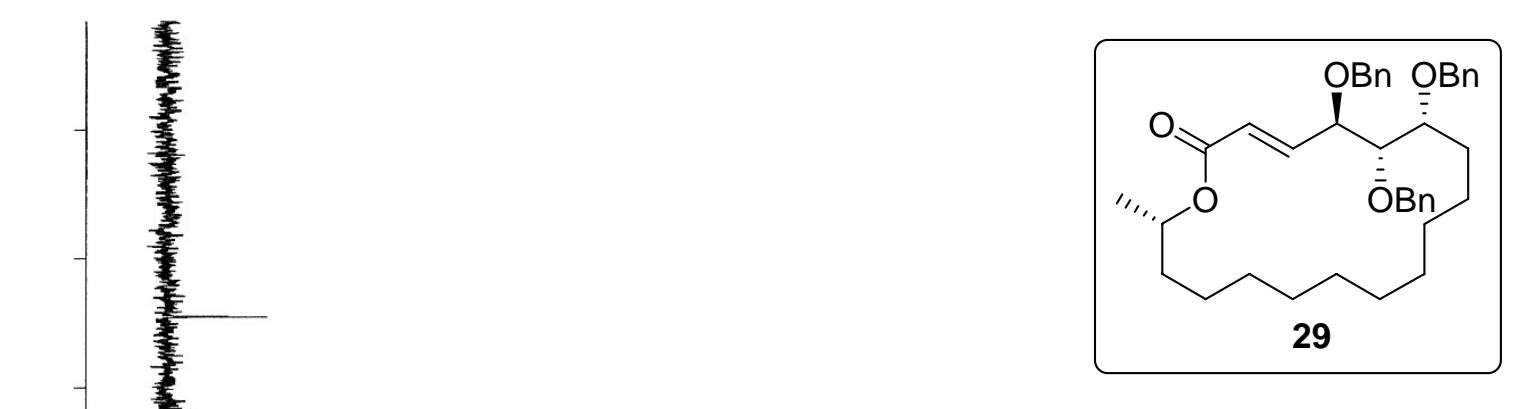




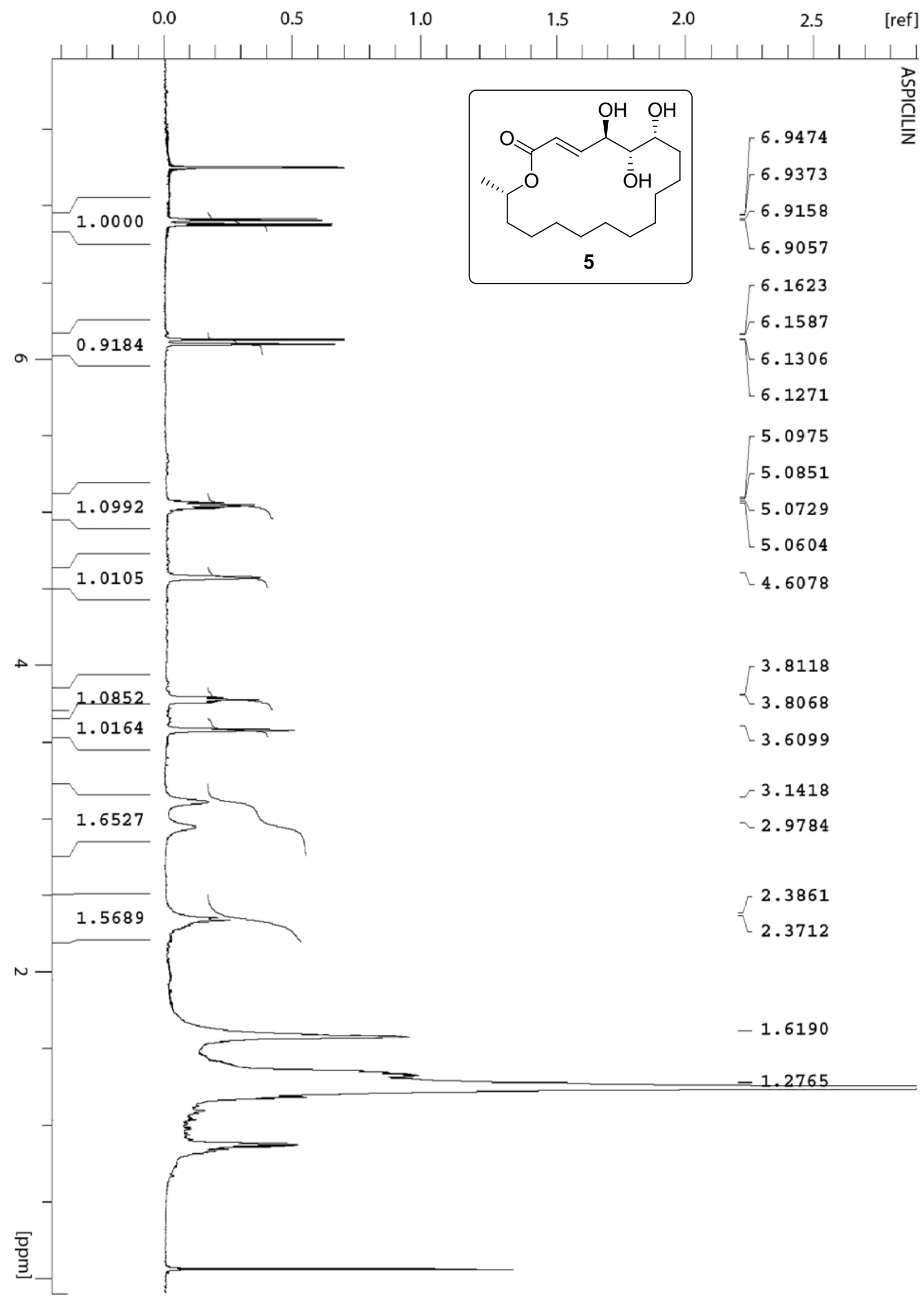




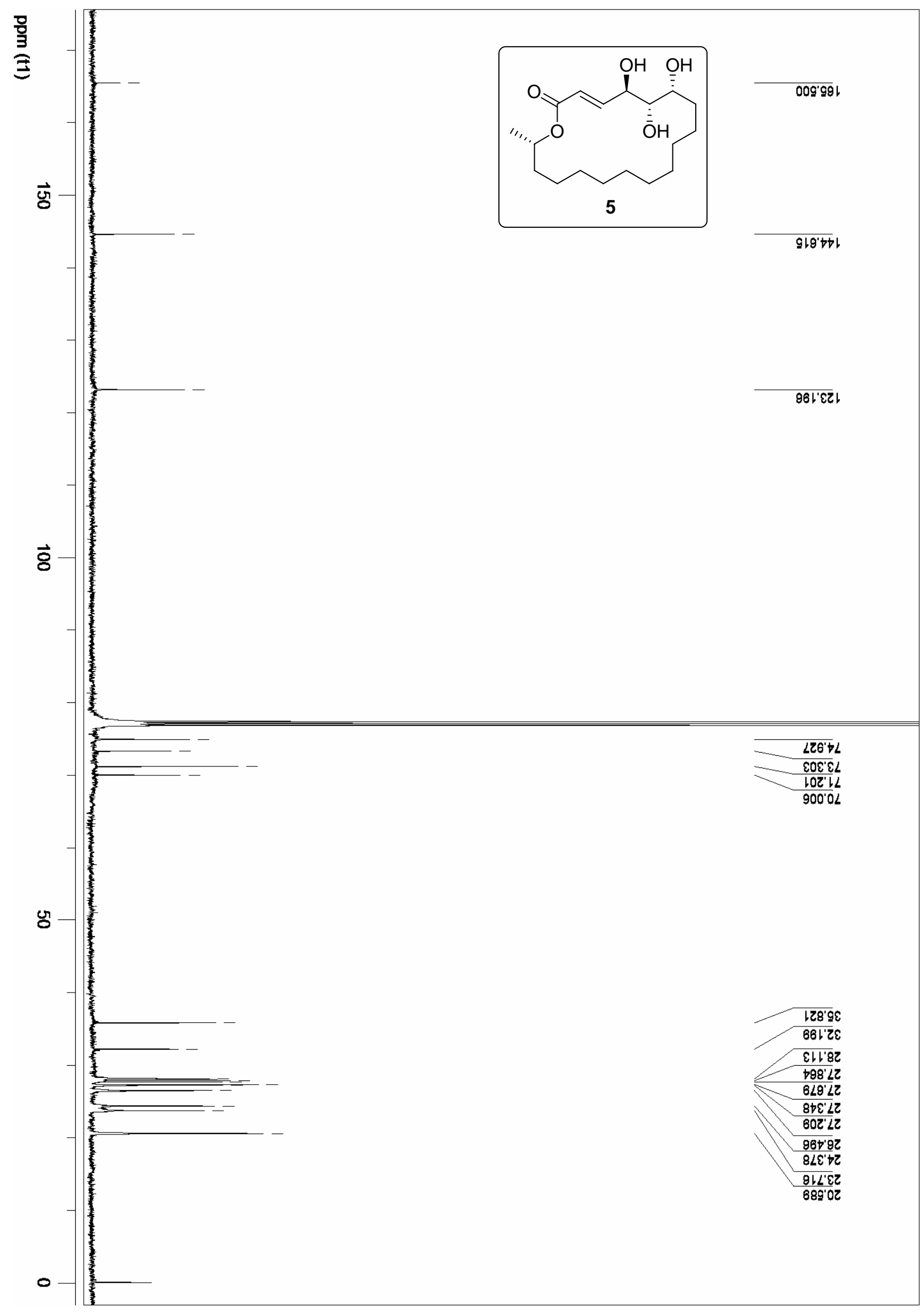

